\title{
O SENADO FEDERAL E A DELIBERAÇÃO DE ATOS INTERNACIONAIS NO PRESIDENCIALISMO BRASILEIRO**
}

\section{Simone Diniz}

\section{Introdução}

As análises relacionadas com as questôes externas podem ser organizadas em torno de dois grandes grupos: (i) a escola dos realistas das relações internacionais, que considera o Estado um ator unitário e coerente, e nega a importância da política e dos atores domésticos na negociação internacional, ou afirma normativamente que tal influência é prejudicial (Waltz, 2002; Morgenthau, 1951, 2003; Kennan, 1984); e (ii) e a vertente que ressalta a importância da incorporação de fatores

* Este texto foi elaborado com base no projeto de pesquisa "Poder Legislativo, processo decisório e política externa”, financiado pela Fapesp. A autora contou também com bolsa de produtividade em pesquisa do Conselho Nacional de Desenvolvimento Científico e Tecnológico.

Artigo recebido em 17/02/2011

Aprovado em 21/05/2012 domésticos na explicação do processo de negociação e deliberação.

Duas premissas são centrais neste último grupo: a análise da política externa não deve se limitar apenas a considerações do sistema internacional e ao chamado "interesse nacional", típico das análises clássicas de relações internacionais; e a percepção de que os interesses nacionais são mutáveis, dependendo, por exemplo, do partido que está no poder ou da força dos grupos de interesse (Rosenau, 1966; Hermann, 1969; Allison, 1971; Putman, 1988; Milner, 1997; Martin, 2000).

No que diz respeito à participação do poder Legislativo na política externa, no âmbito nacional, os estudiosos dividem-se entre os que negam a ocorrência de atuação dos parlamentares no pós-1988 ou que a consideram insignificante nas questôes externas e aqueles que buscam apresentar evidências daquela atuação ou que a interpretam como inerente às práticas democráticas (Lima 
e Santos, 2001; Neves, 2003; Maia e Cesar, 2004; Oliveira, 2004; Alexandre, 2006; Diniz e Ribeiro, 2008 e 2010; Diniz, 2009).

Tendo em vista que o propósito deste artigo é analisar a ação do Senado Federal na deliberação dos atos internacionais negociados pelo poder Executivo brasileiro e encaminhados para deliberação, concentrar-me-ei nos estudos que buscam incorporar o poder Legislativo na análise da política externa.

O artigo está organizado em quatro seçoes. A primeira apresenta uma revisão da literatura relativa ao quadro de análise sobre a importância de fatores domésticos nas questōes externas. A segunda faz um relato sobre a evolução da participação do Legislativo na celebração dos atos internacionais. A terceira trata do debate constituinte de 1986-1987, no Brasil, sobre a participação do poder Legislativo nas questôes de política externa. A quarta apresenta a atuação dos senadores no processo de deliberação. A última dedica-se a retomar os principais pontos discutidos no artigo.

\section{Política externa versus fatores domésticos}

É recente na literatura nacional a vinculação entre política externa e política doméstica (Lima, 2000; Alcântara, 2001; Ratton Sanchezm et al., 2006). Na literatura internacional esta vinculação já se manifestava em meados da década de 1960. Rosenau (1966), por exemplo, identifica dois pontos de entrave para o que chamou de "evolução da teoria de política externa”: um seria de natureza filosófica e estaria relacionado com a dificuldade em se estabelecer relaçóes de causalidade nos estudos de política externa; outro trataria de um problema de ordem conceitual relacionado com a distinção rígida entre questôes internas e externas. ${ }^{1}$ Hermann (1969, p. 231), ao elucidar fatores que poderiam auxiliar os analistas na explicação de algumas açôes da política externa, ressalta que nas relaçōes internacionais prevalecem dois tipos de enfoques: um, denominado sistêmico, engloba um conjunto de atores (externos, nacionais, organizações internacionais) que atuam reciprocamente dentro de padróes estabelecidos e mediante estruturas previa- mente designadas; outro, denominado "tomada de decisão", diz respeito ao processo mediante o qual se adotam as decisóes em matéria de políticas, inclusive a externa. Em relação a este último, um elemento central é a "organização" (o locus operacional da decisão), o que implica no reconhecimento da participação de outros atores no processo de tomada de decisão.

Allison (1971), por sua vez, diferentemente de Rosenau e Hermann, elabora a análise articulando questóes de ordem teórica e empírica. O livro discorre sobre a crise dos mísseis cubanos de 1962, levando em conta não apenas o contexto internacional da Guerra Fria, como também os fatores domésticos para explicar a atuação dos Estados Unidos naquele episódio. $\mathrm{O}$ autor apresenta três modelos de análise do processo de tomada de decisão: o racional, o organizacional e o burocrático.

O primeiro modelo (racional) tem por característica a confiança na premissa de "nações unidas" por um propósito em comum. Esse enfoque tende a amenizar as complicaçôes organizacionais à simplificação de um ator único, o que é um equívoco, de acordo com Allison. No modelo organizacional, o elaborador da política governamental é um conglomerado de grandes organizações e de atores políticos que diferem substancialmente sobre o que seus governos deveriam fazer em relação a algum assunto e competem no intento de influenciar tanto as decisões como as açôes do governo. Segundo o modelo burocrático, o que um governo realiza em qualquer caso particular pode ser entendido como resultado de negociaçôes entre os atores imbricados em hierarquias. Tanto as negociações como os resultados são afetados por várias restriçōes: procedimentos organizacionais e valores compartilhados. $\mathrm{O}$ modelo não considera somente um ator, mas muitos atores como executantes, os quais se dividem não em termos de um conjunto congruente de objetivos estratégicos, mas sim em função de concepções de interesse de segurança nacional, organizacionais, internos e pessoais. Portanto, as decisōes não são tomadas mediante uma escolha individual e racional, mas sim a partir das imbricaçôes de vários fatores e com a presença de inúmeros atores.

Já na década de 1980, Putnam (1988), também examinando a vinculação entre fatores inter- 
nos e externos, tomou como objeto de análise as reuniões de cúpula econômica envolvendo países ocidentais, a negociação referente ao Canal do Panamá e o Tratado de Versalhes, para enfatizar o papel das preferências, das coalizōes, das instituiçôes, das práticas domésticas, das estratégias e táticas dos negociadores, da incerteza, das reverberaçóes domésticas advindas de pressóes externas e o papel dos interesses do negociador-chefe. Para o autor, a luta política em negociações internacionais pode ser concebida como um jogo de dois níveis. No âmbito nacional, os grupos domésticos perseguem seu interesse pressionando o governo a adotar políticas que lhes sejam favoráveis, e os políticos buscam o poder constituindo coalizões entre esses grupos. No âmbito internacional, os governos nacionais buscam maximizar suas próprias habilidades de satisfazer as pressões domésticas, enquanto minimizam as consequências adversas das evoluções externas. Nenhum dos dois jogos pode ser ignorado pelos tomadores de decisão, pois seus países permanecem ao mesmo tempo interdependentes e soberanos.

Duas outras referências obrigatórias são Milner (1993 e 1997) e Martin (2000). Para Milner (1993), a estrutura das preferências domésticas é um elemento-chave para a compreensão da cooperação internacional, sendo primordiais as preferências dos atores domésticos. O Executivo, o Legislativo e os grupos de interesse são atores centrais nas questôes externas e a posição assumida por um desses atores influenciará a posição dos demais, cabendo verificar qual deles tem maior capacidade de determinação e influência. $\mathrm{O}$ resultado da disputa interna dá à coalizão vencedora o direcionamento da política externa.

Em outro trabalho Milner (1997) afirma que se deve levar em conta a forma institucionalmente estabelecida de interação entre os poderes Legislativo e Executivo. Para ela, o peso do arranjo institucional doméstico sobre as negociaçôes internacionais pode ser avaliado pelo exame detido da organização do processo decisório e das prerrogativas constitucionais dos poderes no interior das instituições estatais. O papel relevante do Congresso decorre do fato de ser ele o principal locus de atuação direta dos partidos e principal órgão de representação dos diversos interesses da sociedade.
Martin (2000), dedicando-se especificamente à ação dos poderes Executivo e Legislativos norte-americanos e dos países que formam a União Europeia, desenvolve a análise a partir de três questōes centrais: (i) o Legislativo participa da política externa? (ii) entre as democracias, há variação no modelo de participação legislativa e, em caso afirmativo, o que a explica? (iii) a participação do Legislativo afeta a capacidade das democracias para firmarem acordos críveis com outros Estados? A participação do Legislativo influencia o resultado da cooperação internacional? Quais as consequências da influência legislativa?

Sua análise revela que, de um lado, há participação do Legislativo na política externa. A influência legislativa, embora discreta, é maior do que geralmente se supõe, porque as legislaturas retêm múltiplos mecanismos para frustrar a implementação de acordos internacionais; de outro, o envolvimento do Legislativo na cooperação internacional aumenta a capacidade de as democracias firmarem compromissos críveis, comprometendo-se com a cooperação. A participação institucionalizada do Legislativo fornece ao Executivo e a outros Estados uma informação mais apurada sobre as preferências dos parlamentares e da sociedade, reduzindo as chances de renegar, além de criar obstáculos institucionais para a mudança da policy, aumentando sua estabilidade. Além disso, a influência legislativa canalizada pelas instituições domésticas varia sistematicamente na resposta para conflitos de interesse entre Executivo e Legislativo. O grau de discricionalidade leva o presidente dos Estados Unidos e da União Europeia a diferentes caminhos.

No Brasil, sob forte influência dos trabalhos de Milner e Martin, alguns pesquisadores passaram a mapear as possíveis formas de ação dos deputados federais (Maia e Cesar, 2004; Alexandre, 2006; Diniz e Ribeiro, 2008 e 2010; Diniz, 2009). Os resultados indicam que, por preceito constitucional, o âmbito para atuação dos parlamentares (seja dos deputados federais seja dos senadores) é bastante limitado, tendo em vista que: (i) o presidente da República tem a prerrogativa privativa de celebrar tratados, convençōes e atos internacionais (artigo 84, inciso VIII da CF/88); (ii) na deliberação dos atos internacionais a ação do Legislativo é ex post: 
os parlamentares se manifestam, após negociação prévia estabelecida pelo Executivo com agentes externos, por meio dos projetos de decretos legislativos; (iii) os parlamentares expressam a anuência ou a discordância com os termos e com o conteúdo que compõem o ato internacional; (iv) a possibilidade de emenda ou de aprovação parcial, por meio de ressalvas apresentadas pelos parlamentares, está restrita aos decretos legislativos ${ }^{2}$ (Diniz, 2009).

$\mathrm{O}$ ato internacional, assim como qualquer outra proposição legislativa, é um instrumento por meio do qual a política pública se materializa. Sendo assim, é passível de obstrução por setores oposicionistas através da apresentação de ressalvas (ainda que limitadas, conforme ressaltado anteriormente) ou de rejeição do ato internacional. Tal como ocorre com outras proposições, é de se esperar também que o poder Executivo tente controlar o processo legislativo com o objetivo de assegurar a aprovação de suas preferências por determinadas políticas.

Figueiredo e Limongi (1999) já demonstraram o quanto os pedidos de urgência são primordiais para assegurar o sucesso do Executivo nas matérias referentes à política doméstica. Mais do que determinar o tempo para apreciação, a solicitação de urgência põe nas mãos dos presidentes das mesas e do colégio de líderes recursos significativos para assegurar a aprovaçãa à proposição de interesse do Executivo. O mesmo padrão foi encontrado no que diz respeito aos acordos internacionais (Diniz e $\mathrm{Ri}$ beiro, 2010).

Em resumo, mais até do que na política doméstica, os preceitos da Constituição Federal e os mecanismos de controle da agenda, a saber, capacidade de determinar o tempo de apreciação das proposiçôes, de influenciar a composição, indicação de presidentes e de relatores das comissões permanentes à disposição do poder Executivo, restringem significativamente o campo de atuação do poder Legislativo na deliberação dos acordos internacionais. Por essas razões, se o pesquisador se concentrar apenas nas "taxas de sucesso ou fracasso" - quantidade de atos internacionais aprovados ou rejeitados, ou quantidade de ressalvas apresentadas -, chegará à conclusão de que o Legislativo conta muito pouco nas questôes externas e que tem pouco interesse nessas matérias.
O ponto de partida deste artigo é: dadas as limitações institucionais impostas ao poder Legislativo no que diz respeito à deliberação dos atos internacionais, deve-se buscar outras formas de aferição $\mathrm{da}$ ação parlamentar. Conforme indicado anteriormente, os trabalhos realizados no Brasil tendem a se concentrar na Câmara dos Deputados. Aqui a atenção estará voltada para a atuação dos senadores.

A análise empreendida segue alguns parâmetros utilizados em artigos anteriores (Diniz e Ribeiro, 2008, 2010; Diniz 2009), a saber: (i) atos internacionais que receberam algum tipo de reser$\mathrm{va}^{3}$ e (ii) outras formas de participação que possam revelar a atuação dos parlamentares na deliberação dos atos submetidos ao seu exame e a manifestação de clivagens inter e intrapartidárias sobre temas específicos, como, por exemplo, o registro de votos contrários expressando divergências de posicionamento, a solicitação de informações a membros do Executivo; a solicitação de vistas, de adiamento de discussão e/ou votação, de apreciação por outras comissões e de deliberação por votação nominal.

Diniz e Ribeiro (2008) mostraram que, de um total de 725 projetos de decreto legislativo relativos a acordos internacionais, apenas 47 receberam aprovação parcial na Câmara dos Deputados. No que diz respeito à ação dos senadores, apenas 14 atos internacionais sofreram algum tipo de intervenção. Isso é pouco diante da quantidade de mensagens enviadas para deliberação, mas a despeito da natureza exploratória deste estudo, as evidências revelam que não se pode afirmar que os senadores brasileiros são indiferentes às questôes externas ou que seu comportamento se apresenta de forma coesa e isenta de clivagens inter e intrapartidárias.

\section{O poder Legislativo e a celebração dos atos internacionais}

De acordo com Medeiros (1983), até meados do século XVIII, a conclusão dos atos internacionais dos Estados era prerrogativa exclusiva dos monarcas. As relações internacionais consistiam em relações entre soberanos, e os tratados eram concluídos por estes ou em seu nome. Consequentemente, não poderiam existir tratados inconstitucionais, 
tampouco era cogitada a questão da validade interna dos mesmos.

A Constituição norte-americana foi a primeira a incluir o poder Legislativo no processo de celebração de tratados internacionais, mas foi com a Revolução Francesa e os trabalhos da Assembleia Constituinte que o controle do poder Legislativo sobre os atos internacionais evoluiu. Para os constituintes franceses, juridicamente, um tratado obriga o Estado e, por consequência, os cidadãos; e, politicamente, os tratados internacionais e toda a política externa são assunto não apenas dos governantes, mas também dos governados (Medeiros, 1983 , p. 28).

Assim, o advento da era do constitucionalismo e da democratização dos sistemas políticos ocasionou o término dos poderes discricionários dos chefes de Estado na conclusão de acordos internacionais. A vontade do Estado deixou de ser a do soberano e passou a ser a vontade do povo. Daí a imposição de submeter os tratados ao exame e aprovação do parlamento (Idem, p. 32).

O Executivo, como representante internacional do Estado, continuava com as atribuições de negociar, assinar e ratificar tratados e convenções. Entre as diversas fases processuais, entretanto, e precisamente depois da assinatura e antes da ratificação, interpôs-se uma formalidade de direito interno que condicionava a própria ratificação e que se consubstanciava na aprovação pelo poder Legislativo (Idem, p. 34). ${ }^{4}$

A Constituição norte-americana detém a precedência histórica em atribuir competência ao poder Legislativo para aprovar tratados internacionais. $\mathrm{O}$ artigo II, seção 2 , inciso 2 da carta determina que o presidente tem poderes para, com o conselho e o consentimento do Senado, concluir tratados, desde que autorizado pelo voto de dois terços dos senadores presentes. ${ }^{5}$ No entanto, o sistema norte-americano passou a admitir vários tipos de atos internacionais, os quais o presidente pode concluir por si mesmo, sem a obrigação de obter o consentimento do Senado. Trata-se dos chamados acordos executivos que, mesmo não sendo expressamente autorizados pela Constituição, têm sido aceitos, pois são celebrados pelo presidente em atendimento aos poderes constitucionais paralelos, tais como os de comandante das forças armadas e condutor supremo da política externa, entre outras explicações. ${ }^{6}$

Em 1831 o sistema constitucional belga, entendendo não ser necessário submeter ao Legislativo acordos de importância reduzida e considerando a urgência com que certos atos internacionais precisam vigorar, passou a enumerar quais tratados ou convenções precisam de aprovação parlamentar. Haveria dois tipos diferentes de acordos entre Estados: 1) aqueles que podem ser concluídos somente pelo Executivo; 2) os relacionados com o comércio e as finanças do Estado, ou que modifiquem a legislação interna vigente, os quais devem receber o consentimento preliminar das câmaras. Assim, ficaram delineadas duas tendências antagônicas quanto à participação do poder Legislativo na celebração de tratados (Idem, p. 35), que se manifestam em diversos países, inclusive no Brasil.

\section{O Senado Federal e a Constituição brasileira de 1988}

No sistema político brasileiro, as negociações internacionais são de competência do poder Executivo. Os principais órgãos responsáveis pela condução da política externa são o Ministério das Relaçôes Exteriores e o presidente da República. O congresso nacional tem competências limitadas, e um de seus principais instrumentos é a apreciação dos atos internacionais negociados pelo Executivo.

A deliberação de um ato internacional inicia-se na Câmara dos Deputados e uma vez aprovado é encaminhado para deliberação do Senado Federal. ${ }^{7}$

A Constituição brasileira criou um Senado Federal semelhante em termos de estrutura e funçôes ao norte-americano. Apesar disso há diferenças importantes entre as prerrogativas dos senadores nos dois países. As mais relevantes para este estudo são a capacidade de os senadores norte-americanos emendarem atos internacionais e atuarem ex ante.

Durante os trabalhos da Assembleia Nacional Constituinte de 1986-1987 (ANC), a posição dos constituintes membros da subcomissão "Do Poder Legislativo" era claramente no sentido de ampliar as prerrogativas dos parlamentares. A principal demanda era a obrigatoriedade da deliberação pelo 
congresso nacional acerca de todo e qualquer compromisso internacional celebrado pelo poder Executivo, principalmente aqueles relacionados com empréstimos externos. Foi proposto que o congresso nacional deveria se manifestar previamente à celebração de acordos internacionais e tentou-se assegurar, ao Senado Federal, caráter exclusivo e com poder de veto nas questóes relativas ao endividamento externo, o que gerou acirrado debate entre deputados e senadores. ${ }^{8}$

Ponto consensual entre os parlamentares constituintes foi o descontentamento quanto à prática do Executivo de celebrar atos internacionais e não submetê-los à apreciação do congresso nacional, especialmente aqueles referentes a acordos com o Fundo Monetário Internacional.

De acordo com relato do deputado constituinte Bocayuva Cunha (PMDB), o congresso nacional perdeu a prerrogativa de examinar o endividamento externo, com a expedição de um decreto-lei durante o período militar. A partir de então, segundo relato dos constituintes Itamar Franco (PL) e José Jorge (PFL), passou a vigorar a tese de que o congresso nacional apenas tomaria conhecimento dos atos, convênios e tratados iniciais firmados pelo presidente da República, sem interferir em suas consequências, ainda que estas viessem a ser lesivas ao interesse do país (relatório da Constituinte, vols. 105 e 107).

Ainda no âmbito da referida subcomissão, houve divergência quanto à necessidade ou não de todo e qualquer ato ser submetido à deliberação dos parlamentares. Para o então senador Fernando Henrique Cardoso (PMDB) apenas alguns atos internacionais deveriam ser apreciados pelo poder Legislativo, "cabendo a esse especificar quais classes de atos internacionais passariam pelo seu crivo, e até onde iria a autonomia do poder Executivo nessa matéria" (relatório da Constituinte vol. 107).

$\mathrm{Na}$ subcomissão do poder Executivo, a condução dos trabalhos foi menos custosa. Tratava-se basicamente de manter o que já existia - papel preponderante do Executivo na celebração de atos internacionais.

A Comissão de Sistematização aprovou a participação do congresso nacional na celebração dos tratados, convenções e atos internacionais. O tex- to que foi para deliberação do plenário ampliava a competência exclusiva do congresso nacional no controle dos compromissos externos com a inclusão, no Inciso I do Art. $5^{\circ}$, do dispositivo que vincula a vigência de tais atos à aprovação via decreto legislativo (relatório da Constituinte vol. 109).

Encerrados os trabalhos da ANC, o texto constitucional aprovado estabelece que:

Art. 49 - É competência exclusiva do Congresso Nacional:

I - resolver definitivamente sobre tratados, acordos ou atos internacionais que acarretem encargos ou compromissos gravosos ao patrimônio nacional; 9

XIV - aprovar iniciativas do Poder Executivo referentes às atividades nucleares;

Compete privativamente ao Senado Federal:

- autorizar operaçôes externas de natureza financeira, de interesse da União, dos Estados, do Distrito Federal, dos Territórios e dos $\mathrm{Mu}$ nicípios;

- dispor sobre limites globais e condições para as operações de crédito externo e interno da União, dos Estados, do Distrito Federal e dos Municípios, de suas autarquias e demais entidades controladas pelo poder público federal; - dispor sobre limites e condiçôes para a concessão de garantias da União em operações de créditos externos e internos;

No que se refere à competência exclusiva do presidente da República, foi estabelecido seu poder de celebrar tratados, convenções e atos internacionais, sujeitos a referendo do congresso nacional.

Alexandre (2006, p. 59) relata que a nova Carta, no tocante a tais dispositivos, foi recebida de forma muito negativa. Os artigos que definem as competências do Legislativo e do Executivo usam termos distintos ao espelhar a relação entre os poderes na celebração de tratados. Fala-se de tratados, convenções e atos internacionais ao se tratar da competência do Executivo, e em tratados, acordos ou atos internacionais que acarretem encargos ou compromissos gravosos ao patrimônio nacional, com relação ao Legislativo. Além disso, o texto 
constitucional dá margem a duas correntes divergentes de interpretação sobre os acordos internacionais que prescindam da aprovação do Legislativo. Segundo a autora, alguns juristas entendem que há obrigatoriedade da aprovação pelo congresso acerca de todo e qualquer compromisso internacional celebrado pelo Executivo, ao passo que outros advogam pela existência de acordos internacionais, concluídos pelo Executivo, e válidos, independentemente da chancela do Legislativo, entendimento que prevalece na prática política brasileira (Rodas, 1991 apud Alexandre, 2006).

\section{O Senado Federal e os atos internacionais}

O fato de os parlamentares brasileiros não disporem de prerrogativas de emendamento direto ao próprio texto do ato internacional ou de se manifestarem ex ante tem sido interpretado como ausência de participação e/ou de interesse nas questões externas. Corrobora esta interpretação o fato de o congresso nacional aprovar a grande maioria dos atos internacionais e poucos deles receber algum tipo de ressalva.

Há limites institucionais para a atuação dos parlamentares, conforme já mencionado anteriormente, mas isto não nos credencia a afirmar que eles estejam desinteressados ou alheios às questôes externas. O desafio é encontrar possíveis indicadores que expressem a atuação dos membros do Legislativo no processo de deliberação das proposições que tratam dos temas internacionais.

Do ponto de vista político institucional, alguns procedimentos adotados no decorrer da tramitação dos atos internacionais podem ser utilizados como instrumento de aferição do comportamento dos parlamentares. Tais procedimentos são: apresentação de reservas; solicitação de audiências com representantes do poder Executivo; solicitação de vistas ao processo; registro de votos em separado; solicitação de adiamento da discussão e/ou de votação; ocorrência de debates entre os parlamentares e de votação nominal. ${ }^{10}$

No período coberto pela pesquisa, os senadores se valeram dos procedimentos supramencionados em catorze atos internacionais. Ou seja, eles cola- boraram sobremaneira com o Executivo, tendo em vista que a grande maioria dos atos internacionais foi aprovada tal como enviada pelo Executivo. Não é possível mensurar se essa aprovação ocorreu por concordância total, mas há indicações de que a participação dos parlamentares na atividade de relatoria se concentra, majoritariamente, entre os parlamentares que compõem a base governista (Diniz e Ribeiro, 2008). Portanto, o número expressivo de atos aprovados pode ser decorrente da ação coordenada entre Executivo e base de apoio.

Sobre o suposto desinteresse dos parlamentares, se levarmos em conta, por um lado, as limitações institucionais, a impossibilidade de emendamento e a ação ex post e, por outro, a dinâmica de funcionamento da produção legislativa no Brasil ainda assim os parlamentares apresentam ressalvas, convocam audiências, solicitam vistas, registram voto em separado etc. -, fica difícil sustentar que se trata de falta de interesse. Quantitativamente, o montante pode ser inexpressivo, mas revela que os parlamentares não são meros carimbadores das propostas negociadas pelo Executivo. Há casos em que membros da própria base governista apresentaram reservas ou alguma ponderação sobre pontos específicos dos atos. Em outros, os partidos de oposição apoiaram o ato negociado pelo presidente votando contra procedimentos requeridos por membros da situação.

Uma visão mais pessimista sobre o funcionamento do sistema político brasileiro diria que se trata, mais uma vez, de exemplo do caos que reina no processo decisório. Adoto aqui interpretação diversa. Os casos que passarei a relatar demonstram a atuação dos senadores na deliberação dos atos internacionais, segundo suas crenças e valores.

A apresentação de ressalvas a atos internacionais, quando da tramitação no Senado Federal, entre o conjunto de atos que compuseram esta pesquisa incidiu em quatro casos. Dois atos exemplificam também situações em que o Senado atuou como Casa Revisora, corrigindo aspectos que passaram despercebidos pela Câmara dos Deputados.

Inicio pela Convenção de Estocolmo sobre Poluentes Orgânicos Persistentes, adotada em 2001 pelas Naçôes Unidas, em resposta à necessidade de ação global para proteger a saúde humana e o meio 
ambiente dos referidos poluentes, produtos químicos altamente tóxicos, persistentes, bioacumuláveis. $\mathrm{O}$ ato internacional foi encaminhado para deliberação do congresso nacional pelo presidente Lula. $\mathrm{Na}$ Câmara dos Deputados teve como relator, no âmbito da Comissão de Relações Exteriores (CRE), o deputado Fernando Gabeira (PV), cujo parecer destaca o artigo $3^{\circ}$ da Convenção, que, entre outros aspectos, dispóe sobre medidas que os signatários da Convenção deverão adotar para proibir ou eliminar a produção e a utilização de poluentes orgânicos persistentes. Essa preocupação foi incorporada ao decreto legislativo visando evitar que se "crie situação jurídica que possibilite a importação de resíduos de poluentes orgânicos que não tenham sido aqui produzidos ou exportados" (documento de tramitação do PDC 818/03, disponível em <www.camara.gov.br>, parecer do relator pp. 4 a 7 , acesso em 26/1/11). A Convenção seguiu para tramitação no Senado Federal, tendo como relator o senador Juvêncio da Fonseca (PSDB), que corrigiu um equívoco de redação que poderia tornar sem efeito a ressalva feita pelo deputado Gabeira. O texto proposto por Gabeira dispunha: "o Brasil apenas poderá efetuar a importação prevista no Artigo $3^{\circ}$, parágrafo 2, alínea (b) i, se tiver sido o país o produtor ou exportador da substância a ser importada, ficando vedadas outras importações com base nesse dispositivo" (documento de tramitação do PDC 818/03, disponível em <www.camara.gov.br>, parecer do relator pp. 4 a 7 , acesso em 26/1/11). A preocupação de Gabeira, no que diz respeito à importação dos produtos em tela, está relacionada com sua alínea "a", inciso i, e não com a alínea "b".

Poder-se-ia argumentar que se trata apenas de uma emenda de redação, portanto, sem importância significativa. No entanto, vale ressaltar, que um simples problema de "redação" inviabiliza a mudança substantiva da reserva aprovada na Câmara dos Deputados. Uma primeira leitura que levasse em conta apenas a vinculação partidária do presidente que enviou e do parlamentar que emendou poderia interpretar este caso, equivocadamente, como uma relação de conflito entre Executivo e Legislativo, o que não corresponde aos fatos.

Dois outros projetos de decreto legislativo encaminhando atos internacionais, negociados pelo presidente Fernando Henrique, foram emendados pelos senadores, mas em ambos os casos as emendas foram rejeitadas. Um refere-se ao acordo para isenção de impostos federais, estaduais e municipais relativos à implementação do projeto do gasoduto Brasil-Bolívia (PDC 337/96), relatado pelo senador Pedro Simon (PMDB). O outro caso refere-se ao Protocolo adicional ao Tratado de Assunção (pdc 64/95), com emenda apresentada pelo senador Roberto Requiāo. ${ }^{11}$

Vimos que é pequena a incidência de apresentação de emendas (ou reservas) tanto no momento de deliberação no Senado como na Câmara dos Deputados. ${ }^{12}$ Defendo aqui, tal como Maia e Cesar (2004), que a participação dos parlamentares na deliberação dos atos internacionais, mesmo que seja uma atuação mais assertiva, não se limita à apresentação de reservas aos projetos de decretos legislativos. Há outros mecanismos de atuação parlamentar que também recaem sobre o processo decisório, o que mostra não somente as ocorrências de outras formas de participação, como também exemplifica situações de acirradas divergências quanto ao conteúdo substantivo de certos atos internacionais. Parlamentares desinteressados não desperdiçariam tempo e energia debatendo questôes que não lhes interessam. O registro de votos contrários é uma forma de os parlamentares registrarem o seu desacordo com a aprovação da matéria. Essa discordância manifestou-se nos casos relatados a seguir.

O presidente Fernando Henrique encaminhou para deliberação do Congresso Nacional o Acordo firmado com os Estados Unidos, dispondo sobre cooperação na aplicação de suas leis de concorrência (PDC 1042/01). O acordo foi relatado pelo senador José Agripino (PFL), que apresentou parecer favorável à aprovação. Manifestando-se contrário àquela decisão, o senador Tião Viana (PT) apresentou voto em separado, justificando do seguinte modo:

No âmbito das relações econômicas com o Brasil e o resto do mundo, há, da parte dos Estados Unidos, uma grande distância entre as intenções e os gestos. Como se sabe, em 5 de março próximo passado, o presidente Bush, acolhendo parecer da Comissão de Comér- 
cio Internacional e valendo-se do que dispóe a legislação comercial norte-americana, impôs salvaguardas nas importações de aço, as quais, segundo o ministro Sérgio Amaral em depoimento no plenário do Senado Federal, implicarão, para a indústria siderúrgica nacional, o prejuízo da ordem de US\$ 1 bilhão em suas exportaçôes. Assim, se é o próprio governo norte-americano, ao promover práticas anticompetitivas que afetam interesses de outros países, quem adota medidas impeditivas do livre comércio, não há por que sustentar o presente acordo (Diário do Senado Federal de 4/6/2002, p. 10143).

Outro caso de registro de voto contrário incidiu sobre o Acordo entre Brasil e Estados Unidos para fornecimento de material de defesa norte-americano (PDC 639). O senador José Fogaça (psdb), designado relator, apresentou parecer pela aprovação. Adotando posição contrária, o senador Lauro Campos (PT) assim se posicionou:

[...] não posso concordar com o fato de que o Brasil se transforme, uma vez que foi proibido de desenvolver o setor armamentista, as atividades bélicas, espaciais e atômicas, num paiol ou num espaço para armazenar as armas obsoletas que os Estados Unidos já não podem mais guardar (Diário do Senado Federal de 11/10/2000, p. 20232).

Este posicionamento refletia a opinião de parte dos membros do bloco da oposição, formado basicamente pelos partidos de esquerda, mas não de sua totalidade, razão pela qual a senadora Heloísa Helena (PT) encaminhou a votação, liberando o bloco para votar segundo a vontade de cada membro (Idem, ibidem). Vale lembrar que sua posição refletia o reconhecimento de que havia, mesmo entre os petistas, parlamentares dispostos a apoiar o acordo, não somente no Senado Federal como também na Câmara dos Deputados, haja vista que o relator da matéria em primeira instância que apoiou a medida foi o deputado José Genoino (PT).

Também ao Protocolo para Prorrogação do Acordo de Cooperação em Ciência e Tecnologia, entre Brasil e Estados Unidos, encaminhado pelo presidente Itamar (PDC 67/95), foi registrado voto contrário. O senador Hugo Napoleão (PFL) apresentou parecer favorável à matéria. A senadora Benedita da Silva (PT) solicitou vistas e em seguida voto contrário. ${ }^{13}$

A deliberação dos dois atos relatados a seguir implicou, para além do registro de voto em separado, pedidos de vista e de adiamento de discussão e votação. Trata-se do Segundo e do Quinto Protocolo ao Acordo Geral sobre o comércio de serviços da Organização Mundial do Comércio (OMC), encaminhados pelo presidente Fernando Henrique (pdc 284/96 e PDC 391/00).

Para relatar o II Protocolo foi designado o senador Lúdio Coelho (PSDB), que apresentou parecer favorável à aprovação. Seu relatório informa que:

[...] o acordo é o primeiro assinado sob a vigência da OMC. Por essa razão, tem especial significado para o sistema multilateral de comércio, mesmo não tendo sido assinado pelos Estados Unidos, que o consideram pouco liberalizante. Não obstante, crêem todos os demais participantes, entre os quais os países da União Europeia e o Japão, que o acordo contribuirá para a liberalização do sistema financeiro mundial em moldes multilaterais, impedindo que frutifiquem tentativas unilaterais por parte dos países de impor aos demais determinados modelos ou esquemas de liberalização (Diário do Senado Federal de 5/3/2002, p. 1351).

Contrários à aprovação do acordo, os senadores Geraldo Candido (PT) e José Agripino (PFL) solicitam vistas. Com a aprovação do parecer na Comissão de Relações Exteriores, Geraldo Candido apresenta voto contrário, sob a seguinte justificativa:

$\mathrm{Na}$ sua exposição de motivos, o sr. presidente da República assinala que o acordo sob exame contribuirá para a liberalização do sistema financeiro mundial em moldes multilaterais, aduzindo ainda que para o Brasil a participação nesse acordo tem a vantagem adicional de reafirmar, perante nossos parceiros na OMC, 
a intenção do governo brasileiro de promover, no futuro, uma maior abertura do sistema nacional à competição internacional. Ocorre que a Constituição de 1988, ao dispor sobre o sistema financeiro nacional, determinou que lei complementar estabelecesse as condições para participação do capital estrangeiro nas instituições, tendo em vista, especialmente: a) os interesses nacionais e b) os acordos internacionais. [...] A meu juízo, somente deveríamos deliberar sobre essa matéria, após a edição da lei complementar a que se refere o artigo 192 da Constituição Federal (Diário do Senado Federal de 5/3/2002, p. 1352).

Após aprovação do parecer na Comissão de Relações Exteriores, o parecer foi encaminhado para deliberação do plenário. Na seção de deliberação (9/4/2002), o senador Suplicy (PT) solicitou adiamento da discussão e da votação para que se pudesse aprofundar estudos sobre o tema (Diário do Senado Federal de 10/4/02, p. 4220). Vencido o prazo, o senador José Eduardo Dutra (PT) solicita novo adiamento sob a seguinte justificativa:

[...] movimentos especulativos contra a moeda brasileira dos últimos dias, orientados, inclusive pelos bancos que recentemente passaram a atuar no mercado nacional, reforçam a necessidade de um debate mais profundo sobre a presença de capital estrangeiro no sistema bancário brasileiro. Ocorre que o artigo 192 da Constituição Federal [...] infelizmente ainda não foi regulamentado. Por esta razão sugerimos o retorno da matéria à Comissão de Relaçôes Exteriores, para aprofundamento do seu estudo, inclusive com a deliberação da lei complementar conforme determinação constitucional (Diário do Senado Federal de 23/5/2002, p. 8886).

O pedido foi aprovado, e em 27/6/2002 a matéria estava pronta para entrar na pauta. Aproximou-se o fim da legislatura e o Senado não deliberou. $\mathrm{O}$ acordo foi redistribuído para diferentes senadores sem, no entanto, se consumar sua deliberação. Finalmente, em setembro de 2007 o se- nador Romeu Tuma (PFL), indicado como relator, manifesta-se favoravelmente à aprovação:

[...] os compromissos a que se refere o Segundo Protocolo, vinculam o Brasil a um patamar mínimo de liberalização do setor, que salvo melhor juízo, não ameaçaria o empresariado nacional. [...] Tampouco parece ferir os ditames constitucionais quanto ao Sistema Financeiro Nacional (Diário do Senado Federal de 26/9/2007, p. 32658).

A posição adotada por Tuma estava respaldada na aprovação da Emenda Constitucional 40 de 2003 de autoria do senador José Serra (PSDB), modificando o artigo 192 da Constituição.

A exposição de motivos que acompanha o Quinto Protocolo ao Acordo Geral sobre o Comércio de Serviços, da OMC (PDC 391/00) informa que no decorrer das negociaçôes, o Brasil apresentou uma lista de compromissos específicos, consubstanciada em oferta de serviços financeiros e dividida em dois subsetores: seguros e serviços relacionados e bancos e outros serviços financeiros, com vistas ao aprofundamento de oferta de serviços já apresentada em 1995 , mas respeitando outras questôes que dependem de regulamentação do artigo 192 da Constituição federal (Exposição Motivos, Diário do Senado Federal de $14 / 11 / 2001$, p. 28452).

O relator Romeu Tuma apresentou parecer favorável em novembro de 2001, mas a matéria não foi a voto devido ao pedido de adiamento da discussão apresentado pelo senador José Eduardo Dutra (PT), sob a seguinte justificativa:

[...] as tratativas, no âmbito da OMC sobre a questão de liberalização dos serviços financeiros, consoante o GATS, obedecem uma ordem cronológica sequencial. Assim, o Quinto Protocolo só pode ser considerado, em função do que foi aprovado no Segundo Protocolo, dada a sistemática de construção de consensos. Por esse motivo, impõe-se o retorno da matéria à CRE, para que essa, primeiramente, conclua a apreciação do Segundo Protocolo, para, aí sim, levar a efeito a apreciação do Quinto (Diário do Senado Federal de 23/11/2001, p. 29305) 
Tabela1

Tempo de Tramitação dos PDLS por Governo - 1988 a 2006

\begin{tabular}{|c|c|c|c|c|c|c|c|c|}
\hline $\begin{array}{l}\text { Tempo de } \\
\text { tramitação }\end{array}$ & $\begin{array}{l}\text { Sarney } \\
15 / 3 / 1985 \\
a \\
15 / 3 / 1990\end{array}$ & $\begin{array}{l}\text { Collor } \\
15 / 3 / 1990 \\
a \\
2 / 10 / 1992\end{array}$ & $\begin{array}{l}\text { Itamar } \\
2 / 10 / 1992 \\
a \\
1 / 1 / 1995\end{array}$ & $\begin{array}{l}\text { FHC (1) } \\
1 / 1 / 1995 \\
a \\
1 / 1 / 1999\end{array}$ & $\begin{array}{l}\text { FHC (2) } \\
1 / 1 / 1999 \\
a \\
1 / 1 / 2003\end{array}$ & $\begin{array}{l}\text { Lula (1) } \\
1 / 1 / 2003 \\
a \\
1 / 1 / 2007\end{array}$ & $\begin{array}{l}\text { Lula (2) } \\
1 / 1 / 2007 \\
a \\
1 / 1 / 2011\end{array}$ & Total \\
\hline 1 a 3 meses & 2 & 4 & 6 & 10 & 7 & 6 & - & 35 \\
\hline 4 a 6 meses & 1 & 4 & 4 & 12 & 1 & 2 & - & 24 \\
\hline 7 a 9 meses & 3 & 9 & 3 & 41 & 7 & 3 & - & 66 \\
\hline 10 a 12 meses & 1 & 8 & 7 & 46 & 8 & 18 & - & 88 \\
\hline 13 a 18 meses & - & 22 & 14 & 37 & 40 & 36 & 3 & 152 \\
\hline 19 a 24 meses & - & 6 & 7 & 28 & 47 & 35 & - & 123 \\
\hline 25 a 36 meses & - & 8 & 7 & 30 & 32 & 43 & 12 & 132 \\
\hline 37 a 42 meses & - & - & 1 & 10 & 3 & 18 & 4 & 36 \\
\hline Mais que 43 & - & - & & 11 & 5 & 37 & 16 & 69 \\
\hline Total & 7 & 61 & 49 & 225 & 153 & 198 & 35 & 725 \\
\hline
\end{tabular}

Fonte: Diniz e Ribeiro (2008).

$\mathrm{Na}$ sessão de 2/4/2002, a matéria estava pronta para entrar na pauta com parecer favorável à aprovação. O senador Tião Viana (PT) solicitou vistas ao processo e ao devolvê-lo apresentou voto contrário e pedido de sobrestamento da matéria, até que fosse editada a legislação complementar que regularia o artigo 192 da Constituição Federal (disponível em <www.camara.gov.br>, documento de tramitação do PDC 391/00). Encerrou-se a legislatura e, tal qual o Ato anterior, a matéria somente foi aprovada em 2007.

Uma crítica comumente feita à atuação dos congressistas é a demora na deliberação das proposiçōes. No entanto, é fato conhecido que protelar uma decisão pode ser uma medida mais eficaz para manutenção do status quo, no lugar de levar a matéria a voto para rejeitá-la. A utilização dos pedidos de urgência por parte das lideranças partidárias da base governista, para além de ser um mecanismo para tornar o processo decisório mais célere, é, também, uma forma de evitar pontos de veto, como por exemplo, as comissões permanentes.

No que diz respeito ao tempo de tramitação dos atos internacionais, embora não tenhamos um parâmetro quanto ao limite para considerar que uma deliberação foi célere ou não, o fato é que $59 \%$ (de um total de 725 atos) foi deliberado em no máximo 18 meses, conforme indica a Tabela 1.

A longa tramitação do segundo e do quinto protocolos ao Acordo Geral sobre o Comércio está relacionada com a necessidade de adequação da legislação doméstica, no caso específico, uma emenda constitucional, com todas as implicações que esse tipo de proposição impõe (quórum qualificado, votação em dois turnos em cada casa legislativa e votação nominal). Não fosse assim, a aprovação dos protocolos previamente à mudança constitucional geraria controvérsias jurídicas por colidir com a legislação nacional em vigor. Outra forma de manifestação dos congressistas são os pedidos de adiamento de discussão e/ou votação. Os senadores recorreram a esses expedientes nos projetos que trato a seguir, todos encaminhados pelo presidente Fernando Henrique.

O primeiro refere-se ao Protocolo de defesa da concorrência do Mercosul (PDC 781/99), tendo como relator o senador Artur da Távola (PSDB), que apresentou parecer favorável na Comissão de Relaçôes Exteriores. Anunciada a matéria em ple- 
nário, foi lido e aprovado requerimento solicitando adiamento da discussão para reexame da Comissão, subscrito pelo próprio relator pelo senador Bernardo Cabral (PFL).

Outra matéria que teve adiamento de discussão e votação foi o Protocolo adicional ao Acordo de cooperação financeira entre Brasil e Alemanha (PDC 626/98).

O referido protocolo tem por objetivo isentar a Companhia Estadual de Tecnologia e Saneamento Ambiental - Cetesb, sediada em São Paulo, do pagamento de impostos relacionados com a importação de equipamentos destinados à implementação do projeto denominado "Monitoramento da Qualidade das Águas do Rio Tietê”. O senador José Agripino (PFL) apresentou parecer favorável, mas quando da manifestação do plenário o senador Gilberto Miranda (PFL) solicitou e obteve adiamento da discussão para que a Comissão de Assuntos Econômicos também deliberasse sobre o acordo (Diário do Senado Federal de 16/4/1998, p. 6579).Quando da votação do requerimento em plenário, o senador Romeu Tuma (PFL) solicitou a Gilberto Miranda (PFL) que abrisse mão do requerimento de adiamento, tendo em vista a urgência da recuperação do rio Tietê. A resposta foi de que não era possível a isenção de IPI sem que a matéria fosse analisada pela Comissão de Assuntos Econômicos e complementou seu argumento nos seguintes termos:

Acredito senador que mais uma semana ou quinze dias não irão prejudicar o monitoramento do rio Tietê. Ao contrário, ser for feito o monitoramento das águas desse rio paulista, o resultado será zero, pois nele e também no Pinheiros não foram utilizados os financiamentos que concedemos tanto para saneamento como limpeza e, consequentemente, para o tratamento das águas, que demorará, no mínimo cinco anos (Diário do Senado Federal de 16/4/1998, p. 6579).

$\mathrm{Na}$ Comissão de Assuntos Econômicos foi designado como relator o senador Jorge Bornhausen (PFL), que se manifestou favoravelmente à aprovação do acordo de cooperação (Diário do Senado Federal de 16/4/98, p. 8281).
O acordo comercial entre Brasil e Indonésia (PDC 658/98) exemplifica o uso político de um ato internacional, embora a matéria tratasse, tão somente, de acordo aduaneiro, tarifas de comércio e isenções tributárias. Foi relatora da matéria a senadora Emilia Fernandes (PT), que apresentou parecer favorável à aprovação. Em plenário, no momento da deliberação, a senadora solicitou e obteve o adiamento da discussão. As razóes para tal pedido foram assim explicitadas:

[...] analisamos esta matéria na CRE, mas fatos recentes, acontecidos e divulgados pela imprensa nacional nos fizeram pedir o seu adiamento. A matéria publicada no Jornal do Brasil descreve um violento e covarde ataque de forças paramilitares contra timorenses. Tal ataque pode por fim ao acordo de cessar fogo e às eleições diretas marcadas para julho, com o objetivo de decidir pela independência ou autonomia do território ocupado. [...] A aprovação desse acordo poderia ser vista, a nível internacional, como um endosso a uma atitude de extrema covardia (Diário do Senado Federal de 9/4/1999, p. 7673).

$\mathrm{O}$ adiamento vigorou por trinta dias e quando a matéria entrou na pauta, a senadora solicitou novo adiamento, mas desta feita não obteve sucesso. $\mathrm{O}$ requerimento foi considerado prejudicado e o acordo foi aprovado.

$\mathrm{Na}$ deliberação da Convenção sobre a eliminação de todas as formas de discriminação contra a Mulher (PDC 374/01) registrou-se um intenso debate no Senado Federal, onde foram acionados diversos mecanismos institucionais e intensa atuação de membros da Igreja Católica, representados pela Conferência Nacional dos Bispos do Brasil (CNBB). A matéria foi relatada pela senadora Emília Fernandes (PT) que apresentou parecer favorável à aprovação. Ao entrar na pauta para deliberação do plenário, o senador Tião Viana do mesmo partido que a senadora solicitou e conseguiu adiamento da discussão. A senadora manifestou sua surpresa quanto ao pedido de adiamento da discussão, nos seguintes termos: 
[...] surpreende-me que somente agora, no plenário, venha este pedido de adiamento da discussão [...]. Hoje, recebi das mãos do Secretário Geral da CNBB um ofício pedindo o adiamento da votação. Fico surpresa ao verificar este pedido. O Protocolo amplia a cidadania das mulheres na defesa dos direitos humanos. Trata-se de instrumentos simplesmente procedimentais, que não criam novos direitos, nem dizem o que o Brasil tem de estabelecer em termos de direitos da mulheres [...]. Precisamos discutir a violação dos direitos das mulheres, que continuam sendo mutiladas em diversos países e sendo exploradas pela máfia da prostituição. Ninguém vai impor nada, nem ao Congresso Nacional, nem ao poder Judiciário. Que se tranquilize a Igreja. Lamento que o Senado adie algo que o presidente da República, as organizações não governamentais e todos os parlamentares da Câmara aprovaram. É uma demonstração de retrocesso em relação àquilo que vem sendo discutido no planeta inteiro. Submeto-me ao requerimento, mas, ainda que informalmente, para instruir este Protocolo, pretendemos realizar audiências públicas, porque dessa forma vamos dirimir os problemas (Diário do Senado Federal de 26/4/2002, p. 6179).

O senador Roberto Freire (PPS) também se pronunciou contrário ao requerimento de adiamento, afirmando que "o que pretende a CNBB é a rejeição, pelo Senado, da ratificação desse acordo internacional" (Diário do Senado Federal de 26/4/2002, p. 6180). Em contrapartida, a senadora Marina Silva (PT) manifestou-se favorável ao requerimento e saiu em defesa da CNBB: "nesse documento a CNBB não está solicitando a mobilização contra o projeto, pede apenas que o assunto seja discutido com mais cautela" (Diário do Senado Federal de 26/4/2002, p. 6181).Emilia Fernandes não se conteve e novamente se manifestou:

Respeito a CNBB [...] mas lamento que tenha sido procurada aqui. É uma desconsideração para comigo, pois fui relatora desse processo que está na Casa desde março. Qual foi o movimento feito na Câmara, que aprovou por unanimidade? Por que não foram ao presidente da República dizer que não mandasse esse protocolo? Quero que isto fique claro. Ele veio pensando que eu era autora do projeto. Imagine! A desinformação é total (Diário do Senado Federal de 26/4/2002, pp. 6182).

Em junho do mesmo ano a matéria voltou a ser debatida em plenário, com a presença de representantes do Movimento das Mulheres, do poder Executivo, da sociedade civil e da Igreja (CNBB). Os debates foram dos mais acalorados. Ao final da audiência o senador Carlos Patrocínio (PTB) apresentou novo requerimento de adiamento $\mathrm{da}$ votação alegando a necessidade de "analisar mais profundamente o conteúdo da matéria” (Diário do Senado Federal de 6/6/2002, pp. 10543 e ss). Mais uma vez Roberto Freire posicionou-se contra o adiamento e a favor da votação do protocolo:

[...] a questão [...] é que não podemos ficar à mercê de divergências internas das igrejas brasileiras [...]. Penso que o adiamento tem um sentido procrastinador. E pior: tem a finalidade de impedir que este país afirme aquilo que é uma política interna sua, ou seja, superar processos de discriminação em relação à mulher (Diário do Senado Federal de 6/6/2002, p. 10582).

O presidente da mesa deu início ao processo de deliberação do requerimento e, embora o procedimento adotado fosse de votação simbólica, solicitou que os líderes orientassem suas bancadas. O voto "não" rejeitaria o requerimento e o "sim" o aprovaria. As lideranças do governo, do PFL, do PSB e do PT encaminharam voto pelo "não". Os partidos PSDB, PMDB e PPB liberaram as respectivas bancadas e o PDT encaminhou voto "sim". $\mathrm{O}$ requerimento foi rejeitado, com quinze votos a favor e quarenta contrários.

Para encerrar, mencionarei um último caso: trata-se da Convenção 171 e o Protocolo de 1990 relativos à Convenção 89 de 1948, da Organização Internacional do Trabalho sobre trabalho noturno, encaminhada para deliberação pelo presidente 
Collor.Em 1990, por intermédio de uma Portaria do Ministério do Trabalho, foi criada uma comissão tripartite (governo, empresários e trabalhadores) para discutir os dois instrumentos. Em abril do ano seguinte, essa comissão encerrou seus trabalhos sugerindo a aprovação da Convenção (com voto contrário dos representantes dos empresários) e a rejeição do Protocolo, por entendê-lo como um ato discriminador em relação às mulheres. Os deputados federais acataram a sugestão da comissão tripartite sobre o Protocolo e aprovação na íntegra da Convenção. Encaminhada ao Senado, o relator da matéria, senador Tião Viana (PT) apresentou parecer favorável, com a apresentação de emenda substitutiva, explicitando seu desacordo com a adesão do Brasil ao Protocolo de 1990 e pela aprovação da Convenção 171. No entanto, o relator deveria pronunciar-se somente sobre a Convenção, uma vez que o Protocolo já havia sido rejeitado pelos deputados, e os senadores não poderiam reverter a decisão da primeira Casa. Como o substitutivo apresentado por Tião Viana já havia sido aprovado na Comissão de Relações Exteriores do Senado, fazia-se necessário que o plenário rejeitasse a emenda, por ele apresentada, que fazia menção aos dois documentos, para assim aprovar tão somente a Convenção 171, como de fato ocorreu. Neste caso, a atuação dos senadores foi irrelevante quanto ao mérito, ${ }^{14}$ mas a importância em relatar esses fatos é alertar para a quão arriscada poderá ser a análise se nos limitarmos a quantificar rejeição ou aprovação (de emendas ou de qualquer tipo de proposição). A apresentação de uma emenda (por parte de um membro da oposição) e sua posterior rejeição poderia ser interpretada como mais um exemplo da relação de conflito entre os poderes, sem expressar, no entanto, a verdade dos fatos.

\section{Consideraçôes finais}

A presença de maioria parlamentar no Congresso e de poder de agenda do Executivo são fatores importantes para explicar o sucesso do poder Executivo em termos de resultados legislativos (Döring, 1995; Figueiredo e Limongi, 1999). Não há razōes para se acreditar que, em relação às ques- tôes externas, isso fosse diferente. A aprovação da grande maioria dos atos internacionais submetidos à deliberação dos parlamentares pode ser explicada também por esses aspectos.

Conforme vimos, em geral, a base governista designa relatores e a solicitação de vistas, adiamento de discussão, registro de voto contrário etc. ficam a cargo dos parlamentares da oposiçãa. Seria incorreto afirmar que tais açôes se limitam a uma disputa entre situação e oposição - a última dificultando ao máximo a deliberação de proposiçôes apoiadas pela base governista, pouco importando o conteúdo substantivo do ato internacional.

Um ponto central defendido neste artigo é que os parlamentares são atores interessados em discutir e analisar questões de política externa. A participação dos membros do Legislativo e mesmo uma atuação mais assertiva não se limitam à apresentação de reservas aos projetos de decretos legislativos. Há outros mecanismos de atuação parlamentar que também recaem sobre o processo decisório, demonstrando não somente ocorrências de outras formas de participação dos parlamentares no processo deliberativo, como também exemplificando situações de acirradas divergências quanto ao conteúdo substantivo de certos atos internacionais. Parlamentares desinteressados não desperdiçariam tempo e energia debatendo questóes que não lhes interessam.

Os casos aqui relatados registram clivagens inter e intrapartidárias. Se não houvesse real interesse, parlamentares de um mesmo partido não tornariam públicas divergências de conteúdo dos atos internacionais, a exemplo do que ocorreu na deliberação do Acordo de Cooperação Financeira entre Brasil e Alemanha ou da Convenção sobre a Eliminação de Discriminação à Mulher, o primeiro com posiçōes divergentes entre os parlamentares do antigo PFL (atual DEM) e o segundo, com parlamentares do PT. O acompanhamento da deliberação desta Convenção também mobilizou setores da sociedade, no caso específico, a representação da $\mathrm{CNBB}$, temerosa de que questôes relacionadas com o aborto viessem a ser tratadas em decorrência da aprovação da Convenção.

É fato conhecido que certos atos internacionais, uma vez aprovados e ratificados pelo Executivo, obriga as partes a adequar a legislação domésti- 
ca. Vale registrar que dois casos aqui mencionados, o II e o V Protocolo sobre o Comércio e Serviços da OMC, influenciaram a regulamentação do artigo 192 da Constituição Federal. Note-se que a Emenda 40/03 foi aprovada após o encaminhamento dos referidos protocolos e da manifestação do Legislativo em não aprová-los até que houvesse adequação com o texto constitucional. Conforme registrado anteriormente tais protocolos ficaram pendentes de deliberação, embora houvesse parecer favorável, até que se consumasse a regulamentação do referido artigo da Constituição.

Além do mais, tendo em vista que as questôes externas já não se limitam aos assuntos bélicos e estratégicos dos Estados, voltando-se também para questôes de comércio e investimentos, conforme observou Alcântara (2001) e que muitas vezes tais questôes têm impacto distributivo (Lima, 2000), é ponto pacífico o reconhecimento da legitimidade de participação dos parlamentares senão na formulação, ao menos na deliberação de proposições concernentes à política externa.

\section{Notas}

1 Neste artigo a proposta é antes elucidar aspectos importantes para a elaboração de uma teoria de análise de política externa, e não explicitar, em detalhes, como se articulam questões domésticas e externas.

2 Decreto legislativo é a proposição que, uma vez iniciado o processo de deliberação pelo Congresso Nacional, acompanha o texto do ato internacional.

3 A apresentação de reservas ou ressalvas diz respeito a observações apresentadas e aprovadas pelos parlamentares, tendo em vista que eles estão impedidos de emendar os atos internacionais. Ver Diniz e Ribeiro (2008).

4 Mesmo após a aprovação do Legislativo, os tratados permanecem na situação de projetos, e o chefe do Executivo conserva sua liberdade, podendo ou não ratificá-lo. Os órgãos legislativos não ratificam tratados internacionais; apenas os examinam, dando ou não o seu assentimento, total ou parcial, segundo os diferentes sistemas constitucionais (Medeiros, 1983, p. 46).

5 Outro aspecto do sistema norte-americano de participação do Legislativo é o poder do Senado de emendar tratados submetidos à sua aprovação, ou de formular reservas em relação a eles, obrigando o Executivo a entabular novas negociaçōes com a outra ou as outras partes, se quiser ratificar o tratado (Medeiros, 1983, p. 58).

6 De acordo com Medeiros (1983, p. 55) calcula-se que, de 1787 até a Segunda Guerra Mundial, dos cerca de mil tratados vigentes para os Estados Unidos, aproximadamente duzentos eram acordos executivos. Entre 1946 a 1971, o Departamento de Estado admitiu que foram concluídos 361 tratados e 5.559 acordos executivos. Em $1^{\circ}$ de janeiro de 1972, o número total de acordos internacionais vigentes para os Estados Unidos era de 5.306, dos quais 947 eram tratados formais e 4.359 acordos executivos.

7 Detalhes da tramitação dos atos internacionais podem ser obtidos em Diniz e Ribeiro (2008).

8 Relatório da Constituinte, vol. 107.

9 O constituinte Roberto Campos era contrário a essa proposta, porque, segundo ele, esses "atos requeriam pronta deliberação não podendo aguardar aprovação congressual". Além disso, somente a posteriori poderia verificar se o ato foi danoso ou não (relatório da Constituinte, vol. 109).

10 Diniz e Ribeiro (2010) analisam outros mecanismos de atuação parlamentar, como por exemplo, mecanismos de controle via requerimentos de informação.

11 As informações relativas às datas de publicação no Diário do Senado, contidas nos documentos de tramitação estão incorretas, impossibilitando a localização dos debates.

12 Sobre a deliberação dos Atos Internacionais na Câmara dos Deputados, ver Diniz e Ribeiro (2008 e 2010).

13 Idem nota 10.

14 Agradeço ao parecerista da RBCS por ter me chamado a atenção para esses aspectos. Note-se que o destaque para rejeição da emenda foi apresentado pelo próprio relator.

\section{BIBLIOGRAFIA}

ALEXANDRE, Cristina Vieira Machado. (2006), O congresso brasileiro e a politica externa. Rio de Janeiro, dissertação de mestrado, Instituto de Relaçôes Internacionais, Universidade Católica do Rio de Janeiro (PUC-Rio).

ALLISON, Graham T. (1971), Essence of decision: explaining the Cuban missile crisis. Boston, Little/Brown and Company. 
ALCÂNTARA, Lucio. (2001), "Os parlamentos e as relações Internacionais”. Revista Brasileira de Política Internacional, 44 (1): 13-21.

DINIZ, Simone. (2009), "Atos internacionais e atuação do Legislativo". Teoria e Pesquisa, 18 (1): 27-59.

(2010), "As prerrogativas dos poderes Executivo e Legislativo e a Assembleia Nacional Constituinte de 1987/1988". Trabalho apresentado no V Congresso Latino Americano de Ciência Política - Alacip, de 28 a 30 de julho, Buenos Aires.

DINIZ, Simone \& RIBEIRO, Cláudio Oliveira. (2008), "The role of the Brazilian Congress in foreign policy: an empirical contribution to the debate". Brazilian Political Science Review, 3: $10-38$.

(2010). "Acordos internacionais e controle parlamentar no Brasil". Revista de Sociologia e Politica, 18 (37): 75-92.

DÖRING, Herbert. (1995). Parliaments and majority rule in Western Europe. Mannheim, Centre for European Social Research.

FIGUEIREDO, Argelina \& LIMONGI, Fernando. (1999), Executivo e Legislativo na nova ordem constitucional. Rio de Janeiro, FGV.

HERMMANN, Charles. (1969), "La crisis internacional como variables de situaciones", in James Rosenau (ed.), International politics and foreign policy, Nova York, Free Press of Glencoe.

KENNAN, G. F. (1984), American diplomacy. Chicago, University of Chicago Press.

LIMA, M. R. S. (2000), "Instituições democráticas e política exterior". Contexto Internacional, 22 (2): 265-303.

LIMA, M. R. S. \& SANTOS, F. (2001), "O Congresso brasileiro e a política de comércio exterior". Lua Nova, 52: 121-149.

MAIA, C. C. \& CESAR, S. E. M. (2004), "A diplomacia congressual: análise comparativa do papel dos legislativos brasileiro e norte-americano na formulaçãao da política Exterior”. Revista de Informação Legislativa, 41 (163): 363-388.

MARTIN, L. (2000), Democratic commitments: legislatures and international cooperation. Princeton, Princeton University Press.
MEDEIROS, Antônio Paulo Cachapuz de. (1983). O poder Legislativo e os tratados internacionais. Porto Alegre, L\&PM.

MILNER, Helen. V. (1993), "Maintaining international commitments in trade policy", in $\mathrm{R}$. K. Weaver e B. A. Rockman (eds.), Do institution matter? Washington D.C., The Brookings Instituition.

(1997), Interests, institutions and information: domestic politics and international relations. Princeton, Princeton University Press.

MORGENTHAU, H. (1951). In defense of the national interest. Nova York, Alfred A. Knopf. . (2003), A política entre as naçôes: a luta pelo poder e pela paz. Brasília, Editora da UnB.

NEVES, J. A de C. (2003), "O papel do Legislativo nas negociações do Mercosul e da Alca”. Contexto Internacional 25 (1): 103-138.

OLIVEIRA, Marcelo Fernandes de. (2003), Mercosul: atores políticos e grupos de interesses brasileiros. São Paulo, Editora da Unesp. . (2004), "Atores políticos e parlamento brasileiro no Mercosul". Leviantã, Cadernos de Pesquisa Política, 1: 231-252, Departamento de Ciência Política/USP.

PUTNAM, R. (1988), "Diplomacy and domestic politics: the logic of two-level games". International Organization, 42 (3): 427-461.

RATTON SANCHEZ, Michelle et al. (2006), "Política externa como política pública: uma análise pela regulamentação constitucional brasileira (1967-1988)". Revista de Sociologia e Politica, 27: 125-143.

ROSENAU, James N. (1966), "Pre-theories and theories of foreign policy", in R. Farrell (ed.), Approaches to comparativve and international politics, Evanston IL, Northwestern University Press, pp. 27-92.

WALTZ, K. (2002), Teoria das relaçôes internacionais. Lisboa, Gradiva. 


\section{O SENADO FEDERAL E A \\ DELIBERAÇÃO DE ATOS \\ INTERNACIONAIS NO \\ PRESIDENCIALISMO BRASILEIRO}

Simone Diniz

Palavras-chave: Atos internacionais; Senado Federal; Política externa; Processo decisório.

$\mathrm{O}$ artigo analisa a ação dos senadores brasileiros na deliberação dos atos internacionais negociados pelo poder Executivo. Um ponto central defendido é que os parlamentares são atores interessados em discutir e analisar questôes de política externa. Os preceitos constitucionais impõem limites significativos à ação congressual ao impedir a apresentação de emendas aos atos internacionais ou impossibilitar o controle ex ante, razão pela qual se faz necessária uma busca por outros mecanismos de aferição da atuação parlamentar. Há ocorrências de outras formas de participação dos parlamentares no processo deliberativo, assim como situações de acirrada divergência quanto ao conteúdo substantivo de certos atos internacionais. Parlamentares desinteressados não desperdiçariam tempo e energia debatendo questôes que não lhes interessam.

\section{THE FEDERAL SENATE AND THE DELIBERATION ON INTERNATIONAL ACTS IN BRAZILIAN PRESIDENTIALISM}

Simone Diniz

Keywords: International acts; Federal Senate; Foreign policy; Decision-making process.

This article analyses the action of Brazilian Senators in the deliberation of international acts negotiated by the executive branch. A central point here argued is that lawmakers are interested actors in discussing and analyzing matters of Foreign Policy. Constitutional precepts put significant limits on congressional action, when prevent the submission of amendments to international acts or the impossibility to exercise control ex ante, which is the reason that makes it necessary to look for other mechanisms in order to measure the parliamentary action. The work demonstrates not only occurrences of different forms of participation of parliamentarians in the deliberative process, but also exemplify heated disagreement situations among them, when it comes to the substantive content of certain international acts. Uninterested lawmakers do not waste time and energy debating questions that do not interest them.

\section{LE SÉNAT FÉDÉRAL ET LA DÉLIBÉRATION D'ACTES INTERNATIONAUX DU PRÉSIDENTIALISME BRÉSILIEN}

Simone Diniz

Mots-clés: Actes internationaux; Sénat Fédéral; Politique externe; Processus décisoire.

L'article analyse l'action des sénateurs brésiliens dans la délibération des actes internationaux négociés par le pouvoir Exécutif. Il défend surtout que les parlementaires sont des acteurs intéressés dans la discussion et l'analyse de questions de politique externe. Les préceptes constitutionnels imposent des limites significatives à l'action parlementaire en empêchant la proposition d'amendements aux actes internationaux ou en empêchant le contrôle ex ante, raison par laquelle il est nécessaire de chercher d'autres mécanismes d'évaluation de l'action parlementaire. Il existe d'autres moyens de participation des parlementaires dans le processus délibératif ainsi que des situations de profonde divergence quant au contenu substantif de certains actes internationaux. Des parlementaires désintéressés ne gaspillent pas leur temps et leur énergie à débattre des questions qui ne les intéressent pas. 